\title{
Early Cardiac Changes Due to Doxorubicin Based Chemotherapy and Radiotherapy in Early and Locally Advanced Carcinoma Breast Patients: An Observational Study
}

\author{
Vinin NV ${ }^{1}$, Shyama Prem $\mathbf{S}^{2 *}$, Ajithananathakrishna Pillai ${ }^{3}$, Reddy $\mathrm{KS}^{4}$, Dhanapathi Halanaik ${ }^{5}$ and Sudhakar Kotlapati ${ }^{6}$ \\ ${ }^{1}$ Department of Radiotherapy, Malabar Cancer Centre, Thalassery, Kerala-670103, India \\ ${ }^{2}$ Department of Radiotherapy, RCC, JIPMER, Puducherry-605006, India \\ ${ }^{3}$ Department of Cardiology, JIPMER, Puducherry-605006, India \\ ${ }^{4}$ Mahatma Gandhi Medical College and Research institute, East Coast Road, Pillaiyarkuppam, Puducherry, 607402, India \\ ${ }^{5}$ Department of Nuclear Medicine, JIPMER, Puducherry-605006, India \\ ${ }^{6}$ Department of Radiotherapy, RCC, JIPMER, Puducherry-605006, India
}

*Corresponding author: Shyama Prem S, Associate Professor, Department of Radiotherapy, RCC, JIPMER, Puducherry-605006, India, Tel: 09345324215; E-mail: shyamagopalakrishnan@yahoo.co.in

Received date: June 18, 2015, Accepted date: Aug 03, 2015, Publication date: Aug 05, 2015

Copyright: (C) 2015 Vinin NV, et al. This is an open-access article distributed under the terms of the Creative Commons Attribution License; which permits unrestricted use; distribution; and reproduction in any medium; provided the original author and source are credited.

\begin{abstract}
Objective: To evaluate prospectively the early cardiac changes from doxorubicin based chemotherapy and radiotherapy in breast cancer patients.

Methods and Materials: 56 patients with early or locally advanced breast cancer were included in the study. ECG, ECHO and Equilibrium Radionuclide Ventriculography (ERV) was done at baseline, after chemotherapy, after radiotherapy and at 6 months of follow up.

Results: In Group 1 patients who completed six cycles of chemotherapy before starting radiation, the mean LVEF decreased after chemotherapy and after RT(from $66.79 \pm 3.73$ to $63.45 \pm 3.54$ and $61.64 \pm 4.26, p<0.05$ ). In Group 2 patients who received six cycles of chemotherapy after completion of radiotherapy, mean LVEF decreased post RT and post chemotherapy (from $66.67 \pm 4.33$ to $66 \pm 4.975$ and $62.7 \pm 2.92$, p<0.05). In Group 3 patients also who received neoadjuvant chemotherapy, radiation and adjuvant chemotherapy there was a decline in mean LVEF.In Group 4 patients who received only adjuvant chemotherapy mean LVEF decreased after chemotherapy (from $67.25 \pm 4.33$ to $64.75 \pm 2.062, p<0.05$ ).
\end{abstract}

LVEF was also measured by MUGA/ERV. In Group 1, mean LVEF decreased after chemotherapy and RT (from $58.14 \pm 2.997$ to $56.15 \pm 3.144$ and $56.21 \pm 3.81, p<0.050$. In Group 2 mean LVEF decreased after RT and chemotherapy (from $59.11 \pm 1.41$ to $58.67 \pm 2.872$ and $54.44 \pm 1.81, p<0.05$ ). In Group 3 patients, there was a decline in mean LVEF post neoadjuvant chemotherapy, after radiation and after adjuvant chemotherapy. In Group 4 mean LVEF decreased after chemotherapy (from $60 \pm 1.63$, to $58.75 \pm 1.89, p<0.05$ ).

Conclusion: Our prospective study shows that a significant number of patients can develop a significant transient depression in ventricular function acutely after chemotherapy and radiotherapy as demonstrated by a decrease in LVEF by conventional ECHO and ERV scan.

\section{Keywords: Anthracycline; Post mastectomy radiotherapy; Introduction}

Cardiotoxicity; Equilibrium radionuclide ventriculography

\section{Abbreviations:}

FAC: 5-Fluorouracil Adriamycin Cyclophosphamide; LVEDD: Left Ventricular End Diastolic Diameter; LVESD: Left Ventricular End Systolic Diameter; LVEF: Left Ventricular Ejection Fraction; FS: Fractional Shortening; MVEPSS: Mitral Vlve E Point Septal Separation: PEP: Pre Ejection Period; LVET: Left Ventricular Ejection Time; ERV: Equilibrium Radionuclide Ventriculography; MHD: Mean Heart Doses
Anthracycline based chemotherapy and radiotherapy are an integral part in the primary treatment of breast cancer and majority of the women are offered either one or both the modalities as part of the treatment. The most serious side effect of anthracyclines is chronic cardiotoxicity, which can culminate in congestive the first year after completion of chemotherapy although in some cases it can present many years later [1-3].

Portions of heart are often unavoidably included during irradiation of breast and chest wall. Early effects including pericarditis and reduced cardiac output have been seen at the completion of radiation therapy. ECG abnormalities and reduction in left ventricular ejection fraction were also noticed after radiation treatment of breast cancer 
Citation: Vinin NV, Prem SS, Pillai A, Reddy KS, Halanaik D, et al. (2015) Early Cardiac Changes Due to Doxorubicin Based Chemotherapy and Radiotherapy in Early and Locally Advanced Carcinoma Breast Patients: An Observational Study. J Nucl Med Radiat Ther S7: S7-004. doi:10.4172/2155-9619.1000S7-004

Page 2 of 6

[4]. Prospective randomized trials and meta-analysis have clearly demonstrated that there is an improvement in disease free survival and overall survival with adjuvant anthracycline based chemotherapy [5]. Similarly adjuvant radiation after breast conservation or mastectomy significantly reduces locoregional recurrences and prolongs survival [6].

However these survival gains may be diminished by radiation and chemotherapy associated cardiac morbidity. Many studies have documented the chronic cardiac morbidity. Few studies have documented the early side effects of treatment. It is well established that subclinical cardiac changes can occur during the early phase of treatment and it can progress to chronic cardiac toxicity especially when subjected to an additional non treatment related cardiac stress.

The present prospective study investigated non-invasively the possible early cardiac changes after anthracycline based chemotherapy and radiotherapy in patients with early stage and locally advanced carcinoma breast.

\section{Methods and Materials}

This was a descriptive study. Between October 2010 and July 2011, patients attending the tumour clinic (with early and locally advanced breast cancer), who underwent mastectomy, subject to the inclusion and exclusion criteria were included as the sample.

The diagnosis of breast cancer was made after Tru cut biopsy from the breast lesion. All patients underwent a detailed history and physical examination followed by staging evaluation with complete hemogram, liver and renal function tests, blood sugar and serum electrolytes.

Patients were staged according to the AJCC staging system 7th edition. ChestX-ray and ultrasound abdomen was done in all patients. Patients with Stage III disease also underwent a bone scan for metastatic workup.

All patients with early stage (Stage II) and locally advanced carcinoma breast (Stage IIIA, Stage IIIB, Stage IIIC) who underwent mastectomy, received doxorubicin based chemotherapy [neoadjuvant or adjuvant] and radiotherapy, with ECOG performance score 0 and 1, no history of previous radiotherapy to chest wall or chemotherapy, with normal ECG and echocardiography and without history of any heart disease were included in the study. We did not include patients who underwent breast conserving surgery as we wanted to have a uniform protocol for radiation.

\section{Surgery}

All patients underwent modified radical mastectomy with level 2 lymph node dissection.

\section{Chemotherapy}

All patients received 6 cycles of 5 -Fluorouracil $\left(500 \mathrm{mg} / \mathrm{m}^{2}\right)$, Adriamycin $\left(50 \mathrm{mg} / \mathrm{m}^{2}\right)$ Cyclophosphamide $\left(500 \mathrm{mg} / \mathrm{m}^{2}\right)$ [FAC regimen] on day 1 every 3 weekly. The cumulative dose of Adriamycin was $300 \mathrm{mg} / \mathrm{m}^{2}$ in all the patients.

The dose-intensity of chemotherapy in all patients was $100 \%$.

\section{Radiotherapy}

Radiation therapy was started after hematologic recovery from the last chemotherapy cycle or 4 weeks after mastectomy. External beam radiotherapy [EBRT] was planned using conventional simulation, diagnostic CT scan of the neck and thorax and 3D treatment planning system. CT scan of the neck and thorax was taken using a diagnostic multislice spiral CT scanner with a flat couch.

The position of the patient during diagnostic CT was similar to the position used during RT i.e. with arms abducted and placed beneath the head. All slices were used for dose calculation. Eclipse planning system version 10, AAA algorithm gave the dose delivered to heart. For chest wall irradiationtangential fields [lateral and medial] were used. Supraclavicular fossa and ipsilateral axilla was treated with a direct anterior field prescribed to the mid-plane of axilla. In all patients $6 \mathrm{MV}$ photons were used to deliver 50Gy in 25 fractions to the chest wall and nodal areas.

\section{Cardiac evaluation}

Electrocardiogram: A standard 12 lead electrocardiogram was taken during the study. Any new changes in ECG were recorded.

Echocardiography: Using 2-dimensional echocardiography by Teicholl's method, Left ventricular end diastolic diameter (LVEDD), Left ventricular end systolic diameter (LVESD), Left ventricular ejection fraction (LVEF), Fractional shortening(FS), Mitral valve E point septal separation (MVEPSS), pre ejection period(PEP), Left Ventricular ejection time(LVET) and any other abnormal findings were also recorded.

Equilibrium radionuclide ventriculography: ERV (Equilibrium radionuclide Ventriculography) was performed following in vivo erythrocyte labelling with $740 \mathrm{mBq}$ technetium-99m Pertechnetate. A large-field-of-view gamma camera (Siemens symbia dual head) was used with a low-energy, high-sensitivity collimator to acquire a 16frame gated ventriculogram in a left anterior oblique projection optimized for best separation of the left and right ventricles and with $15^{\circ}$ of caudal tilt. Electrocardiographic gating was used with rejection of cycles following an RR interval outside $15 \%$ of the mean. Acquisition was terminated at a total of 5 million counts. A background corrected left ventricular time activity curve was generated by drawing region of interest over the left ventricle for each frame of the cardiac cycle. End diastole was the frame demonstrating the highest counts and end systole was the frame with the fewest counts.

Ejection Fraction=End diastolic count-End systolic count/End diastolic count

An LVEF of less than 0.50 was considered abnormal. A decrease in LVEF of more than 0.10 was considered to indicate significant cardio toxicity. Wall motion was analysed by viewing a repetitive cinematic closed Loop display on the computer screen.

\section{Statistical Analysis}

Categorical data was presented as frequencies and percentages. Repeated measures of ANOVA were used to assess change in different ECHO and ERV parameters during the study. Paired t- test was used to assess the difference between left and right side for different ECHO and ERV parameters. 
Citation: Vinin NV, Prem SS, Pillai A, Reddy KS, Halanaik D, et al. (2015) Early Cardiac Changes Due to Doxorubicin Based Chemotherapy and Radiotherapy in Early and Locally Advanced Carcinoma Breast Patients: An Observational Study. J Nucl Med Radiat Ther S7: S7-004. doi:10.4172/2155-9619.1000S7-004

Page 3 of 6

\section{Results}

56 patients were included in the study.6 patients were lost to follow up, 1 patient died during study period, 1 patient was excluded from the study as she developed lung metastasis. The details of 48 patients were analysed. The patient characteristics are given in Table 1. In all patients cardiac evaluation was done before treatment, after chemotherapy and radiotherapy and after six months of follow up. According to the sequence of chemotherapy and radiotherapy patients were divided into four groups.

Patients in Group1 completed all 6 cycles of chemotherapy before starting radiotherapy. In Group 2, patients received radiotherapy before starting chemotherapy because of indications like close/positive margins. Patients in Group 3, received neoadjuvant chemotherapy following which surgery was done. Radiation was offered before completing adjuvant chemotherapy. In patients in Group 4 radiation was not indicated, hence they received only six cycles of chemotherapy after surgery. Group 1 had 33 patients while Group 2 had 9 patients, Group 3 had 2 patients and Group 4 had 4 patients. The median age of all patients at the time of treatment was 46 years (range, 28 to 55 years). No difference in age was found between groups I and II (group I: median 48 years, (28 to 55 years) group II: median 46 years, (35-53 years) (Table 1).

\begin{tabular}{|l|l|l|l|l|l|}
\hline \multicolumn{2}{|l|}{ Characteristics } & Group I & Group II & Group III & Group IV \\
\hline \multicolumn{2}{|l|}{ Median age } & 53 & 37 & 48.5 & 45 \\
\hline \multirow{2}{*}{ Stage } & II A & & & & 4 \\
\cline { 2 - 6 } & II B & 11 & 7 & & \\
\cline { 2 - 6 } & III A & 16 & 2 & & \\
\cline { 2 - 6 } & III B & 6 & & 2 & 4 \\
\hline No of patients & 33 & 9 & 2 & \\
\hline
\end{tabular}

Table 1: Patient characteristics.

\section{Cardiac evaluation}

None of the patients developed any cardiac symptoms, clinically apparent CHF or any other cardiac complications within the first 6 months after treatment.

\section{Changes in ECG}

The most common ECG change was $\mathrm{T}$ inversion in the precordial leads.

The changes in ECG in all the groups are given in Table 2.

\begin{tabular}{|l|l|l|}
\hline $\begin{array}{l}\text { ECG } \\
\text { changes }\end{array}$ & $\begin{array}{l}\text { Group } \\
\text { I }\end{array}$ & $\begin{array}{l}\text { 14 patients had ECG changes (12 had Twave inversion , } \\
1 \text { had ST depression \& 1 had ST elevation) }\end{array}$ \\
\cline { 2 - 3 } & $\begin{array}{l}\text { Group } \\
\text { II }\end{array}$ & 2 patients had ECG changes (T wave inversion in both) \\
\cline { 2 - 3 } & $\begin{array}{l}\text { Group } \\
\text { III }\end{array}$ & No patients had ECG changes \\
\hline & $\begin{array}{l}\text { Group } \\
\text { IV }\end{array}$ & 1 patient had T wave inversion \\
\hline
\end{tabular}

Table 2: ECG changes in all groups.

\section{Cardiac parameters in Group I}

In Group I baseline mean LVEF was $66.79 \pm 3.73$ which reduced post chemotherapy to $63.45 \pm 3.54$ and post RT it further reduced to 61.64+4.26 (Table 3). At 6 months of follow up LVEF was $61.42 \pm 3.27$. Pair wise analysis is given in Table 4. Mean LVEF as assessed by ERV at baseline was $58.14 \pm 2.997$ which reduced post chemotherapy to $56.15 \pm 3.144$.Post RT mean LVEF was $56.21 \pm 3.806$ and at 6 months of follow up it reduced further to $55.21 \pm 2.913, \mathrm{p}<0.05$. Mean FS reduced post chemotherapy, post RT and on follow up [from $41.93 \pm$ 4.78 to $40.29 \pm 4.7,38.52 \pm 4.91,38.56 \pm 4.6] \mathrm{p}<0.05$.

Mean (MVEPSS) increased post chemotherapy and post RT from $4.04 \pm 0.78$ to $4.12 \pm 0.83,4.27 \pm 0.72$ respectively. On follow up MVEPSS remained higher than the baseline value [4.2 \pm 0.49$] \mathrm{p}<0.05$. $\mathrm{PEP} / \mathrm{LVET}$ showed an increase post chemotherapy and RT but it was not statistically significant.

\begin{tabular}{|c|c|c|c|c|c|c|c|c|c|}
\hline \multirow[t]{2}{*}{$\begin{array}{l}\text { Para } \\
\text { Meters }\end{array}$} & \multicolumn{2}{|c|}{$\begin{array}{l}\text { (Baseline) } \\
\text { Pre Chemo }\end{array}$} & \multicolumn{2}{|c|}{$\begin{array}{l}\text { Post Chemo } \\
\text { (Pre RT) }\end{array}$} & \multicolumn{2}{|c|}{ Post RT } & \multicolumn{2}{|c|}{ Follow Up } & \multirow[t]{2}{*}{$\begin{array}{l}P \\
\text { value }\end{array}$} \\
\hline & Mean & SD & Mean & SD & Mean & SD & Mean & SD & \\
\hline $\begin{array}{l}\text { LVEF } \\
(\mathrm{ECHO}) \\
(\%)\end{array}$ & 66.79 & 3.73 & 63.45 & 3.54 & 61.64 & $\begin{array}{l}4.2 \\
6\end{array}$ & 61.42 & 3.27 & $\begin{array}{l}<0.000 \\
1\end{array}$ \\
\hline FS (\%) & 41.93 & 4.78 & 40.29 & 4.7 & 38.52 & $\begin{array}{l}4.9 \\
1\end{array}$ & 38.56 & 4.6 & $\begin{array}{l}<0.000 \\
1\end{array}$ \\
\hline $\begin{array}{l}\text { MVEPSS } \\
(\mathrm{mm})\end{array}$ & 4.04 & 0.78 & 4.12 & 0.83 & 4.27 & $\begin{array}{l}0.7 \\
2\end{array}$ & 4.2 & 0.49 & 0.0004 \\
\hline $\begin{array}{l}\text { PEP/ } \\
\text { LVET }\end{array}$ & 0.276 & $\begin{array}{l}0.03 \\
6\end{array}$ & 0.281 & $\begin{array}{l}0.03 \\
2\end{array}$ & 0.286 & $\begin{array}{l}0.0 \\
3\end{array}$ & 0.283 & $\begin{array}{l}0.02 \\
4\end{array}$ & 0.1887 \\
\hline $\begin{array}{l}\text { LVEF } \\
\text { (ERV) (\%) }\end{array}$ & 58.14 & $\begin{array}{l}2.99 \\
7\end{array}$ & 56.15 & $\begin{array}{l}3.14 \\
4\end{array}$ & 56.21 & $\begin{array}{l}3.8 \\
1\end{array}$ & 55.21 & $\begin{array}{l}2.91 \\
3\end{array}$ & $\begin{array}{l}<0.000 \\
1\end{array}$ \\
\hline
\end{tabular}

Table 3: Analysis of cardiac parameters in Group 1.

\begin{tabular}{|l|l|l|l|l|l|l|}
\hline \multicolumn{7}{|l|}{ Pairwise comparison of LVEF (ECHO) in Group 1} \\
\hline & Mean & SD & & Mean & SD & p value \\
\hline \multirow{2}{*}{ Pre chemo } & 66.79 & 3.73 & Post chemo & 63.45 & 3.54 & $<0.001$ \\
\cline { 2 - 8 } & & & Post RT & 61.64 & 4.26 & $<0.001$ \\
\cline { 2 - 8 } & & & Follow up & 61.42 & 3.27 & $<0.001$ \\
\hline Post chemo & 63.45 & 3.54 & Post RT & 61.64 & 4.26 & $<0.05$ \\
\hline (Pre RT) & & & Follow up & 61.42 & 3.27 & $<0.01$ \\
\hline Post RT & 61.64 & 4.26 & Follow up & 61.42 & 3.27 & $>0.05$ \\
\hline
\end{tabular}

Table 4: Pairwise analysis of LVEF (ECHO) in Group 1.

\section{Cardiac parameters in Group II}

Mean LVEF (ECHO) reduced post RT and post chemotherapy (from $66.67 \pm 4.33$ to $66 \pm 4.975$ and $62 \pm 2.915$ ). On follow up mean LVEF reduced further to $61.89 \pm 2.934(\mathrm{p}<0.05)$. In Group II mean LVEF assessed by ERV reduced post RT (from $59.11 \pm 2.472$ to $58.67 \pm$ 2.872. Mean LVEF (ERV) post chemotherapy was reduced to $54.44 \pm$ $1.81(\mathrm{p}<0.05)$. On follow up mean LVEF remained reduced at $55.22 \pm$ 1.787 ( $p>0.05)$ (Table 5). Mean FS reduced post RT and post 
Citation: Vinin NV, Prem SS, Pillai A, Reddy KS, Halanaik D, et al. (2015) Early Cardiac Changes Due to Doxorubicin Based Chemotherapy and Radiotherapy in Early and Locally Advanced Carcinoma Breast Patients: An Observational Study. J Nucl Med Radiat Ther S7: S7-004. doi:10.4172/2155-9619.1000S7-004

Page 4 of 6

chemotherapy (from $39.85 \pm 5.719$ to $39.22 \pm 5.73$ and $39.3 \pm 4.85$ ) On follow up mean FS reduced further to $38.448 \pm 4.024$.

Mean MVEPSS increased post RT and post chemotherapy (from $4.14 \pm 0.577$. to $4.22 \pm 0.507$ and $4.356 \pm 0.475)$. On follow up mean MVEPSS remained prolonged ( $4.33 \pm 0.364)$. PEP/LVET also showed an increase post RT and chemotherapy $(\mathrm{p}>0.05)$.

\begin{tabular}{|c|c|c|c|c|c|c|c|c|c|}
\hline \multirow{2}{*}{$\begin{array}{l}\text { Para } \\
\text { Meters }\end{array}$} & \multicolumn{2}{|c|}{ Pre RT } & \multicolumn{2}{|c|}{ Post RT } & \multicolumn{2}{|c|}{ Post chemo } & \multicolumn{2}{|c|}{ Follow up } & \multirow{2}{*}{$\begin{array}{l}p \\
\text { value }\end{array}$} \\
\hline & $\begin{array}{l}\text { Mea } \\
\mathrm{n}\end{array}$ & SD & $\begin{array}{l}\text { Mea } \\
\mathrm{n}\end{array}$ & SD & $\begin{array}{l}\text { Mea } \\
\mathrm{n}\end{array}$ & SD & Mean & SD & \\
\hline $\begin{array}{l}\text { ECHO } \\
\text { (LVEF) } \\
(\%)\end{array}$ & $\begin{array}{l}66.6 \\
7\end{array}$ & 4.33 & 66 & $\begin{array}{l}4.97 \\
5\end{array}$ & 62 & 2.92 & 61.89 & $\begin{array}{l}2.93 \\
4\end{array}$ & $\begin{array}{l}<0.000 \\
1\end{array}$ \\
\hline FS (\%) & $\begin{array}{l}39.8 \\
5\end{array}$ & $\begin{array}{l}5.71 \\
9\end{array}$ & $\begin{array}{l}39.2 \\
2\end{array}$ & 5.73 & 39.3 & 4.85 & $\begin{array}{l}38.44 \\
8\end{array}$ & $\begin{array}{l}4.02 \\
4\end{array}$ & 0.704 \\
\hline $\begin{array}{l}\text { MVEPSS } \\
(\mathrm{mm})\end{array}$ & 4.14 & $\begin{array}{l}0.57 \\
7\end{array}$ & 4.22 & $\begin{array}{l}0.50 \\
7\end{array}$ & $\begin{array}{l}4.35 \\
6\end{array}$ & $\begin{array}{l}0.47 \\
5\end{array}$ & 4.33 & $\begin{array}{l}0.36 \\
4\end{array}$ & 0.292 \\
\hline $\begin{array}{l}\text { PEP/ } \\
\text { LVET }\end{array}$ & $\begin{array}{l}0.26 \\
7\end{array}$ & $\begin{array}{l}0.02 \\
1\end{array}$ & $\begin{array}{l}0.27 \\
9\end{array}$ & $\begin{array}{l}0.02 \\
9\end{array}$ & $\begin{array}{l}0.27 \\
3\end{array}$ & 0.02 & 0.266 & $\begin{array}{l}0.01 \\
4\end{array}$ & 0.281 \\
\hline $\begin{array}{l}\text { ERV } \\
\text { (LVEF) } \\
(\%)\end{array}$ & $\begin{array}{l}59.1 \\
1\end{array}$ & $\begin{array}{l}2.47 \\
2\end{array}$ & $\begin{array}{l}58.6 \\
7\end{array}$ & $\begin{array}{l}2.87 \\
2\end{array}$ & $\begin{array}{l}54.4 \\
4\end{array}$ & 1.81 & 55.22 & $\begin{array}{l}1.78 \\
7\end{array}$ & 0.0001 \\
\hline
\end{tabular}

Table 5: Analysis of cardiac parameters in Group 2.

\section{Cardiac parameters in Group III}

Group III had only 2 patients and LVEF (ECHO and ERV) decreased post NACT, post RT and post adjuvant chemotherapy. This decrease persisted at 6 months of follow up (Table 6).

\begin{tabular}{|l|l|l|l|l|l|l|l|l|l|l|l|}
\hline $\begin{array}{l}\text { Para } \\
\text { Meters }\end{array}$ & \multicolumn{2}{l|}{ Pre Chemo } & \multicolumn{2}{l|}{ Post NACT } & \multicolumn{2}{l|}{ Post RT } & \multicolumn{2}{l|}{$\begin{array}{l}\text { Post ADJ } \\
\text { Chemo }\end{array}$} & \multicolumn{2}{l|}{ Follow Up } \\
\cline { 2 - 10 } & Mean & SD & $\begin{array}{l}\text { Mea } \\
\mathbf{n}\end{array}$ & SD & $\begin{array}{l}\text { Mea } \\
\mathbf{n}\end{array}$ & SD & $\begin{array}{l}\text { Mea } \\
\mathbf{n}\end{array}$ & SD & $\begin{array}{l}\text { Mea } \\
\mathbf{n}\end{array}$ & SD \\
\hline $\begin{array}{l}\text { ECHO } \\
(\text { LVEF) } \\
(\%)\end{array}$ & 65 & 0 & 63.5 & $\begin{array}{l}0.70 \\
7\end{array}$ & 63.5 & 0.70 & 63 & 0 & 60 & 0 \\
\hline $\begin{array}{l}\text { ERV } \\
(\text { LVEF) } \\
(\%)\end{array}$ & 59.5 & 2.1 & 59 & 1.41 & 58 & 2.83 & 56.5 & 2.1 & 55 & 0 \\
\hline
\end{tabular}

Table 6: Analysis of ECHO and ERV parameters in Group 3.

\section{Cardiac parameters in Group IV}

Group 4 patients received only chemotherapy. LVEF assessed by both ECHO and ERV showed significant reduction $(\mathrm{p}<0.05)$ during the study (Table 7).

\begin{tabular}{|l|l|l|l|l|l|l|l|}
\hline \multirow{2}{*}{ Para Meters } & \multicolumn{2}{l|}{ Pre Chemo } & \multicolumn{2}{l|}{ Post Chemo } & \multicolumn{2}{l}{ Follow Up } & \multirow{2}{*}{ p value } \\
\cline { 2 - 8 } & Mean & SD & Mean & SD & Mean & SD & \\
\hline LVEF (ECHO) (\%) & 67.25 & 2.217 & 64.75 & 2.062 & 63.25 & 2.363 & 0.0037 \\
\hline ERV (LVEF) (\%) & 60 & 1.63 & 58.75 & 1.89 & 56.25 & 2.63 & 0.0383 \\
\hline
\end{tabular}

Table 7: Analysis of cardiac parameters in Group 4.

\section{Left-Sided Versus Right-Sided Radiotherapy}

Mean heart doses (MHD) were 5.625 Gy for left sided cases and $1.887 \mathrm{~Gy}$ for right sided tumours.

\section{Discussion}

The effectiveness of doxorubicin is limited by the cumulative dose related cardiac toxicity and portions of the heart are unavoidably included during irradiation of breast and chest wall. There are only few studies in literature which have analysed the acute cardiac effects of doxorubicin based chemotherapy and radiotherapy in asymptomatic patients during different phases of treatment.

In the current prospective study, we found immediately after chemotherapy a mild but significant impairment of the cardiac function in breast cancer patients treated with relatively low cumulative doses of Adriamycin. This impairment persisted during 6 months after treatment. This was indicated by a decline in the mean LVEF, which was seen in $17 \%$ of the patients showing a decrease from the baseline value. The observed drop in LVEF is a clear indication that even at low cumulative doses, doxorubicin causes impairment of the systolic function as a result of myocardial damage. The magnitude of the mean decline in LVEF in our study is similar to that observed by Cottin et al. who reported a decrease in the mean LVEF from 0.58 to 0.55 twelve months after chemotherapy [7]. None of our patients however recorded a LVEF below 0.50 or a more than 0.1 drop. We had followed the patient for only 6 months and whether this change is stable or progressive can only be determined by serially following the patients. However what is evident is that some myocardial damage has occurred in the acute phase and probably increased their risk for development of congestive heart failure (CHF).

We also studied the effects of radiation on systolic function. We had 2 groups of patients one who received radiation after Adriamycin chemotherapy and a second group which received radiation before anthracyclines. In both the groups there was a decline in LVEF. However only in Group 1, where patients received chemotherapy before RT there was significant reduction in LVEF post RT. This may be explained as the combined effect of chemotherapy and radiotherapy in Group1. Even though in Group 2 post RT there was a decline in LVEF it did not reach statistical significance because the sample size in Group 2 may be insufficient to detect this small change.

LVEF determination was done by 2 methods in our study since intra-observer variation is reported in both the methods. We therefore evaluated the usefulness of other parameters of systolic function and other detection techniques (ERV) to validate our findings.

In Group 1pairwise analyses showed a statistically significant reduction in LVEF (ERV) following chemotherapy, radiotherapy and at 6 months follow up.

In Group 2, mean LVEF (ERV) decreased following radiotherapy, $(p>0.05)$. There was a significant reduction following chemotherapy and LVEF increased during follow up, but it did not reach the pretreatment value.

In Group 3, both the patients analysed showed a decrease in LVEF (ERV) after neoadjuvant chemotherapy, radiation and adjuvant chemotherapy. These changes persisted during follow up. In Group 4 patients also there was a reduction in LVEF (ERV) after chemotherapy which was statistically significant. Perez et al. studied the effect of cumulative doses of doxorubicin of $240 \mathrm{mg} / \mathrm{m}^{2}$ of doxorubicin on 
Citation: Vinin NV, Prem SS, Pillai A, Reddy KS, Halanaik D, et al. (2015) Early Cardiac Changes Due to Doxorubicin Based Chemotherapy and Radiotherapy in Early and Locally Advanced Carcinoma Breast Patients: An Observational Study. J Nucl Med Radiat Ther S7: S7-004. doi:10.4172/2155-9619.1000S7-004

Page 5 of 6

LVEF in patients with breast cancer. In this study LVEF measured by MUGA scan showed a declining trend within 3 weeks of completion of chemotherapy [8]. We also used lower doses of doxorubicin and our study also showed similar changes.

Ikahiemo et al. investigated the incidence and severity of possible radiation induced cardiac changes in breast cancer patients. Parameters assessed were FS, MVEPSS, PEP/LVET ratio. FS decreased between the studies before and immediately after radiation. MVEPSS increased before and immediately after radiation. The PEP/LVET ratio increased between the studies before and immediately after radiation without statistical significance which reverted after 6 months. They concluded that these changes are due to a transient depression in left ventricular function immediately after radiation [9].

We found similar changes in FS and MVEPSS PEP/LVET indicating a depression in left ventricular function after chemotherapy and radiotherapy.

Initial manifestation of chemotherapy/radiation induced heart changes can be a new ECG change. Daher et al. suggested that the most acute and chronic effect of irradiation on heart is repolarisation abnormality [10]. In our study the most common ECG change was $\mathrm{T}$ wave inversion in the precordial leads indicating that an acute repolarisation abnormality was the commonest abnormality after chemotherapy and radiotherapy.

We analysed the number of patients who developed a decrease in LVEF who showed these ECG changes. All patients with ECG changes developed a reduction in LVEF.

Mean heart dose (MHD) for all patients who received chest wall radiation were calculated. Mean heart dose for left side was $5.625 \mathrm{~Gy} \pm$ 2.75 and for right side was $1.887 \mathrm{~Gy} \pm 0.72$. There was no statistically significant difference between in LVEF parameters in the left and right side probably because mean heart dose of 5.625 Gy is not too high to produce a significant change in cardiac function.

The main advantage of our study was that acute cardiac changes due to doxorubicin based chemotherapy and chest wall radiation was extensively studied at different time periods. We also had a good follow up during the study. In more than $90 \%$ of the patients ECHO and ERV on various visits were done by the same physicians, thus avoiding inter-observer variation. The main drawback of our study was that it was underpowered due to the small sample size. Another drawback is the shorter period of follow up. Diastolic dysfunction is known to precede systolic dysfunction. We assessed mainly the systolic changes and probably assessing the parameters of diastolic dysfunction would have added to the value of our study.

Schwartz et al. have developed a monitoring algorithm with scheduled frequent ejection fraction measurements for patients treated with anthracyclines [11]. Will we recommend such intensive cardiac monitoring for all patients receiving anthracyclines and radiation to chest wall? The high incidence of subclinical cardiac dysfunction in our patients reinforces the need for monitoring patients on doxorubicin during different phases of treatment. If radiation is planned after chemotherapy, all the patient detected to have a decrease in LVEF can be considered for intensity modulated radiotherapy where more effort can be made to spare as much as cardiac tissue as possible.

\section{Conclusion}

Our prospective study shows that a significant number of patients can develop a transient depression in ventricular function acutely after chemotherapy and radiotherapy.

Decrease in LVEF was seen in our patients both by conventional ECHO and MUGA/ ERV scan during different phases of treatment which indicate that doxorubicin based chemotherapy and radiotherapy produces acute abnormality in left ventricular function.

Does an acute cardiac change detected on investigating an asymptomatic patient predict the development of chronic cardiac toxicity? This question can only be answered by prolonged follow up, because of the latency of chemotherapy and radiation induced cardiac disease.

\section{Authors Contributions}

VNV- Involved in conception and design, acquisition of data, analysis and interpretation of data and drafting the manuscript.

SSP- Involved in conception and design, acquisition of data, analysis and interpretation of data drafting and revising the manuscript critically.

KSR- Revised the manuscript critically for important intellectual content.

AA- acquisition of data, analysis and interpretation of data.

DH- acquisition of data, analysis and interpretation of data.

SK-acquisition of data, analysis and interpretation of data.

\section{References}

1. Singal PK, Iliskovic N (1998) Doxorubicin-induced cardiomyopathy. N Engl J Med 339: 900-905.

2. Steinherz LJ, Steinherz PG, Tan CT, Heller G, Murphy ML (1991) Cardiac toxicity 4 to 20 years after completing anthracycline therapy. JAMA 266: 1672-1677.

3. Lipshultz SE, Colan SD, Gelber RD, Perez-Atayde AR, Sallan SE, et al. (1991) Late cardiac effects of doxorubicin therapy for acute lymphoblastic leukemia in childhood. N Engl J Med 324: 808-815.

4. Jaworski C, Mariani JA, Wheeler G, Kaye DM (2013) Cardiac complications of thoracic irradiation. J Am Coll Cardiol 61: 2319-2328.

5. [No authors listed] (1998) Polychemotherapy for early breast cancer: an overview of the randomised trials. Early Breast Cancer Trialists' Collaborative Group. Lancet 352: 930-942.

6. Whelan TJ, Julian J, Wright J, Jadad AR, Levine ML (2000) Does locoregional radiation therapy improve survival in breast cancer? A meta-analysis. J Clin Oncol 18: 1220-1229.

7. Cottin Y, Touzery C, Dalloz F, Coudert B, Toubeau M, et al. (1998) Comparison of epirubicin and doxorubicin cardiotoxicity induced by low doses: evolution of the diastolic and systolic parameters studied by radionuclide angiography. Clin Cardiol 21: 665-670.

8. Perez EA, Suman VJ, Davidson NE, Kaufman PA, Martino S, et al. (2004) Effect of doxorubicin plus cyclophosphamide on left ventricular ejection fraction in patients with breast cancer in the North Central Cancer Treatment Group N9831 Intergroup Adjuvant Trial. J Clin Oncol 22: 3700-3704.

9. Ikäheimo MJ, Niemelä KO, Linnaluoto MM, Jakobsson MJ, Takkunen JT, et al. (1985) Early cardiac changes related to radiation therapy. Am J Cardiol 56: 943-946.

10. Daher IN, Kim C, Saleh RR, Plana JC, Yusuf SW, et al. (2011) Prevalence of abnormal echocardiographic findings in cancer patients: a 
Citation: Vinin NV, Prem SS, Pillai A, Reddy KS, Halanaik D, et al. (2015) Early Cardiac Changes Due to Doxorubicin Based Chemotherapy and Radiotherapy in Early and Locally Advanced Carcinoma Breast Patients: An Observational Study. J Nucl Med Radiat Ther S7: S7-004. doi:10.4172/2155-9619.1000S7-004

Page 6 of 6

retrospective evaluation of echocardiography for identifying cardiac abnormalities in cancer patients. Echocardiography 28: 1061-1067.

11. Schwartz RG, McKenzie WB, Alexander J, Sager P, D'Souza A, et al. (1987) Congestive heart failure and left ventricular dysfunction complicating doxorubicin therapy. Seven-year experience using serial radionuclide angiocardiography. Am J Med 82: 1109-1118.

This article was originally published in a special issue, entitled: "Therapeutic Nuclear Medicine", Edited by Maseeh uz Zaman, Aga Khan University Hospital (AKUH), Pakistan 